\title{
Differential Control of Thrombospondin over Synaptic Glycine and AMPA Receptors in Spinal Cord Neurons
}

\author{
Laetitia Hennekinne, ${ }^{1,2,3}$ Sabrina Colasse, ${ }^{1,2,3}$ Antoine Triller, ${ }^{1,2,3}$ and Marianne Renner ${ }^{1,2,3}$ \\ ${ }^{1}$ Ecole Normale Supérieure, Institut de Biologie de l'ENS, IBENS, Paris, F-75005 France, ${ }^{2}$ INSERM, U1024, Paris, F-75005 France, and ${ }^{3}$ CNRS, UMR 8197 , \\ Paris, F-75005 France
}

Thrombospondin-1 (TSP-1) is a large extracellular matrix protein secreted by astrocytes during development and inflammation. In the developing CNS, TSP-1 is involved in neuronal migration and adhesion, neurite outgrowth, and synaptogenesis. We investigated the effects of TSP-1 on neurons with mature synapses using immunocytochemistry, single-particle tracking, surface biotinylation, and calcium imaging. We show that in cultured rat spinal cord neurons TSP-1 decreased neuronal excitability by reducing the accumulation of excitatory AMPA receptors (AMPARs) and increasing that of inhibitory glycine receptors (GlyRs) in synapses. The effects of TSP-1 on GlyRs were dependent on the activation of excitatory receptors. These changes were abolished by blocking $\beta 1$-integrins and mimicked by blocking $\beta 3$-integrins. In the presence of TSP-1, AMPARs were less stabilized at synapses, increasing their lateral diffusion and endocytosis. Interestingly, TSP-1 counteracted the increased neuronal excitability and neuronal death induced by TNF $\alpha$. These results suggest a role of TSP-1 in controlling the balance between excitation and inhibition which could help the recovery of normal synaptic activity after injury responses.

\section{Introduction}

Thrombospondins (TSPs) are large secreted multimeric glycoproteins that play important roles in cell attachment, cell migration, cytoskeletal dynamics, and angiogenesis (Bornstein et al., 2004). TSPs have cell type-specific effects related to their interactions with different extracellular matrix (ECM) molecules, cytokines, and integrins (Murphy-Ullrich and Iozzo, 2012). Thrombospondin-1 (TSP-1) and TSP-2 are expressed by glial cells in the developing CNS, where they participate in neuronal migration and adhesion (Blake et al., 2008), neurite outgrowth (DeFreitas et al., 1995), and synaptogenesis (Christopherson et al., 2005; Eroglu et al., 2009; Xu et al., 2010; Risher and Eroglu, 2012). TSP expression is low in the adult CNS, but its secretion by astrocytes can be induced by purinergic signaling (Tran and Neary, 2006). Indeed, the expression levels of TSP-1 and TSP-2 are upregulated in the case of inflammation or injury (Risher and Eroglu, 2012). TSPs are necessary for synaptic and functional recovery after stroke (Liauw et al., 2008), and play a role in reactive synaptogenesis after nerve injury (Lo et al., 2011). Postinjury inflammatory responses are also characterized by abnormally high levels of the cytokine tumor necrosis factor- $\alpha$ (TNF $\alpha)$,

\footnotetext{
Received Nov. 12, 2012; revised April 16, 2013; accepted May 12, 2013.

Author contributions: L.H., A.T., and M.R. designed research; L.H., S.C., and M.R. performed research; L.H. and M.R. analyzed data; L.H., A.T., and M.R. wrote the paper.

This research was supported by grants from the European Economic Community (MOODINFLAME consortium) the Institut pour la recherche sur la moelle épinière et l'encéphale (IRME), France. L.H.'s salary was paid by the Ministère de la Recherche et de I'Enseignement Supérieur. We thank Cecile Charrier, Samuel Bitoun, and Olivier Pascual for their suggestions and discussion.

The authors declare no competing financial interests.

Correspondence should be addressed to Dr. Antoine Triller, Biologie Cellulaire de la Synapse, Institut de Biologie de I'Ecole Normale Supérieure, Inserm U1024, 46 rue d'Ulm, 75005 Paris, France. E-mail: triller@biologie.ens.fr.

DOI:10.1523/JNEUROSCI.5247-12.2013

Copyright $\odot 2013$ the authors $\quad 0270-6474 / 13 / 3311432-08 \$ 15.00 / 0$
}

which is implicated in the synaptic plasticity phenomenon associated with inflammation and pain (Beattie et al., 2010; Choi et al., 2010). TNF $\alpha$ affects the balance between excitatory and inhibitory synaptic transmission in the hippocampus by increasing the insertion of GluA1-containing AMPARs and reducing the surface amount of GABA receptors (Stellwagen et al., 2005; Beattie et al., 2010).

We investigated the effect of TSP-1 on the distribution and dynamics of both AMPARs and glycine receptors (GlyRs). In mature cultured spinal cord neurons TSP-1 increases glycinergic transmission via $\beta 1$-integrins (Charrier et al., 2010). In contrast, we found that TSP-1 reduced the stabilization of synaptic AMPARs. In consequence, unlike TNF $\alpha$, TSP-1 reduced neuronal excitability. Furthermore, TSP-1 was able to reverse TNF $\alpha$ induced changes on synaptic receptors. These results hint at a role of TSP-1 in controlling the balance between excitation and inhibition and highlight a novel case of regulation of neuronal excitability by glial cells.

\section{Materials and Methods}

Cell cultures. Primary cultures of spinal cord neurons were prepared from Sprague Dawley rats embryos (either sex) as previously described (Charrier et al., 2010). Pure neuron cultures were maintained in neurobasal medium (Invitrogen) conditioned by astrocyte cultures and supplemented with AraC (5 $\mu \mathrm{M})$. Astrocyte cultures were prepared from spinal cords of 14-d-old Sprague Dawley rat embryos and maintained in MEM supplemented with fetal bovine serum (10\%), Na-pyruvate $(1 \mathrm{~mm})$ and glutamine $(2 \mathrm{~mm})$. Once confluent, astrocyte cultures were treated with $\operatorname{AraC}(5 \mu \mathrm{M})$.

Reagents and antibodies. Purified human platelet TSP-1 (Hematologic Technologies) was used at $8 \mathrm{~nm}$ (Charrier et al., 2010) unless indicated. Dynasore, TTX, CNQX, D-AP5, gabapentin, and 4-AP were from Tocris Bioscience. Jasplakinolide (Sigma Aldrich) was used at $100 \mathrm{~nm}$ (Rust et al., 2010) and applied for $30 \mathrm{~min}$ in total (20 min before the addition of 
TSP-1 and $10 \mathrm{~min}$ in presence of TSP-1). Recombinant rat TNF $\alpha$ (PeproTech) was used at $60 \mathrm{~nm}$ (Stellwagen et al., 2005). Monoclonal function-blocking antibodies against integrins $(25 \mu \mathrm{g} / \mathrm{ml})$ were hamster anti-rat $\beta 1$ monoclonal antibody (ab1, clone Ha2/5, BD PharMingen) and mouse anti-rat $\beta 3$ monoclonal antibody (ab3, clone F11, BD PharMingen). Immunodetection was performed using anti- $\alpha$-GlyR (mAb4a or mAb2b, Synaptic Systems), anti- $\alpha 1-$ GlyR (Charrier et al., 2010), anti-GluA1 (Alomone), anti-GluA2 (BD PharMingen or Synaptic Systems), anti-gephyrin (mAb7a, Synaptic Systems), anti-PSD95 (6G61C9, Abcam), anti-Piccolo (kindly provided by E.D. Gundelfinger, Magdeburg, Germany), anti-synapsin (Synaptic Systems), anti-TSP (A4.1, Abcam), Cy3-conjugated goat anti-mouse, Cy5-conjugated donkey anti-guinea pig (Jackson ImmunoResearch) or Alexa 488-conjugated goat anti-rabbit (Invitrogen) antibodies. F-actin was labeled with Alexa 488-phalloidin (Invitrogen).

Immunocytochemistry. The immunolabeling was done as previously described (Charrier et al., 2010). Alternatively, cells were fixed and permeabilized by incubation with methanol at $-20^{\circ} \mathrm{C}(10 \mathrm{~min})$. Imaging was performed on a spinning disk confocal microscope (Leica DM5000B, Leica Microsystems; spinning disk head CSU10, Yokogawa; Photometrics $63 \times$ immersion objective) equipped with a CCD camera (Coolsnap, Princeton Instruments) driven by MetaMorph software (Molecular Devices). Colocalization between synaptic and receptor labeling was determined using the synaptic image as a mask. Quantification of the integrated intensity of colocalized puncta was done using homemade software in MatLab (MathWorks). The intensity of fluorescent spots was averaged for each cell. Percentages of apoptotic nuclei were determined by DAPI (diamidino-2-phenylindole) staining and examining nuclei morphology (Doonan and Cotter, 2008).

Cell surface biotinylation. After $1 \mathrm{~h}$ treatment with TSP-1, cells were washed three times with ice-cold Dulbecco's PBS supplemented with 0.8 $\mathrm{mm} \mathrm{CaCl} 2$ and $0.5 \mathrm{~mm} \mathrm{MgCl}_{2}, \mathrm{pH}$ 7.4. They were then incubated with biotinylation reagent ( $1 \mathrm{mg} / \mathrm{ml}$ NHS-SS-biotin, Pierce) for $25 \mathrm{~min}$ with gentle shaking on ice. After washing and quenching of unbound biotin, cell extracts were collected as described by Charrier et al. (2010). We kept $30 \%$ of the sample as the total receptor fraction. The remaining $70 \%$ was mixed with neutravidin beads (Pierce) for $2 \mathrm{~h}$ at $4^{\circ} \mathrm{C}$ to purify the biotinylated surface proteins. Samples were analyzed by SDS-PAGE followed by immunoblotting and visualized with enhanced chemiluminescence (ECL,+ GE Healthcare). The level of surface receptor was normalized to the corresponding level of total receptor.

Single-particle tracking. After the treatment with TSP-1, cells were rinsed and incubated with the corresponding antibodies and quantum dots for the labeling of single molecules (Charrier et al., 2006). The tracking was performed using homemade software (SPTrack_v4) in MatLab (MathWorks). Given our pointing accuracy, trajectories with a diffusion coefficient $D<10^{-4} \mu \mathrm{m}^{2} / \mathrm{s}$ were classified as immobile.

Calcium imaging. Neurons were incubated before the experiment with TSP-1 (1 h), with TNF $\alpha$ (30 min) or with both applying them sequentially. Neurons were loaded with $1 \mu \mathrm{M}$ Fluo- $4 \mathrm{AM}$ for $5 \mathrm{~min}$ at $37^{\circ} \mathrm{C}$ and incubated for an additional $5 \mathrm{~min}$ before imaging. The imaging was performed at $37^{\circ} \mathrm{C}$ under an inverted spinning disk confocal microscope (Nikon Eclipse Ti; spinning disk head CSUX1-A1, Yokogawa; Leica 63X immersion objective) equipped with an EMCCD camera (Evolve, Photometrics) driven by MetaMorph software (Molecular Devices). The total fluorescence intensity was measured on one region per cell, in a dendrite close to the cell body. The ratio of the fluorescence intensities in comparison with the initial values $\left(F / F_{0}\right)$ was calculated after subtraction of the background fluorescence.

Statistics. Statistical analyses were performed with Prism software (GraphPad) or R software (http://cran.r-project.org/). The normality of the distributions was assessed using one-sample Kolmogorov-Smirnov test. Data obtained by immunocytochemistry were compared using the unpaired Student's $t$ test ( $t$ test) for one-dimensional data and the Hotelling's T-squared test for two-dimensional data. One-factor ANOVA was used for the comparison of several time points with Tukey or linear trend post hoc tests. Diffusion data were analyzed using Kruskall-Wallis test (KW) and Dunn test for post hoc comparisons. Multitemporal data analysis in calcium imaging experiments was performed using a two- factor ANOVA (time/treatment). Differences of proportion between two populations were analyzed with a $\chi^{2}$ test. A test was considered significant when $p<0.05$. All experiments were performed in $2-4$ independent neuron cultures.

\section{Results}

Opposite effects of TSP-1 on the amount of excitatory and inhibitory receptors at synapses

Mixed cultures (neurons and glial cells) were incubated with purified human TSP-1 (8 nM unless indicated, for 10 or $60 \mathrm{~min}$ ). Synaptic GluA2- or GluA1-containing AMPAR or GlyR immunoreactivity (IR) was quantified by coimmunodetecting the receptors with their corresponding scaffolding proteins PSD95 and gephyrin (Fig. 1A). As previously shown (Charrier et al., 2010), TSP-1 application for 60 min increased GlyR IR (35 $\pm 5 \%$ after 60 min; Fig. $1 B$ ). This effect was smaller but significant after a shorter treatment $(17 \pm 4 \%$ after $10 \mathrm{~min}$; Fig. $1 B)$. In contrast, synaptic GluA2 and GluA1 IR were reduced $(19 \pm 3 \%$ and $12 \pm$ $4 \%$, respectively after $10 \mathrm{~min}$ ) with no further decrease after 60 min of treatment (Fig. 1B). The effects of TSP-1 were dosedependent. GlyR IR was monotonically augmented (ANOVA and linear trend $p<0.0001, n=40)$ and AMPARs IR were progressively reduced (GluA1: $p=0.009$; GluA2: $p=0.015 ; n=$ $20-40$ ) with increased concentrations of TSP-1 (between 2 and 8 nM). TSP-1 did not modify the PSD95 IR (ANOVA and Tukey post test; $10 \mathrm{~min}$, not significant; $60 \mathrm{~min}$, not significant), but as previously described (Charrier et al., 2010) gephyrin IR was increased to $119 \pm 4 \%$ of the control after 60 min of treatment (10 min, not significant; $60 \min p<0.001$ ). The treatment with TSP-1 did not change the number of synapses per micrometer of dendrite ( $t$ test, $p>0.07$ )

We next investigated whether the TSP-1 effect was dependent or not on synaptic activity. Cells were treated with TSP-1 (60 min) in presence of either TTX $(1 \mu \mathrm{M}), \mathrm{CNQX}(10 \mu \mathrm{M})$, or D-AP5 $(25 \mu \mathrm{M})$. Under TTX, the reduction of synaptic AMPARs after TSP treatment still occurred, but the effect on GlyRs was abolished (Fig. 1C). Furthermore, the increase of GlyR-IR was abolished in the presence of CNQX, a competitive AMPAR antagonist, or D-AP5, a competitive antagonist of NMDA receptors (Fig. 1D). However, these drugs did not impede the reduction of AMPAR-IR by TSP-1 ( $t$ test, $p<0.0001$ ). Therefore, the effect of TSP-1 on inhibitory receptors needed excitatory receptor activation.

TSP- 1 binds to integrins containing $\beta 1$ - and $\beta 3$-subunits (Carlson et al., 2008), which have opposite effects on GlyR dynamics and accumulation at synapses (Charrier et al., 2010). Neurons were incubated for a short period $(10 \mathrm{~min})$ with antibodies that specifically block integrins by stabilizing their inactive form (Hynes, 2002) before the application of TSP-1 for $10 \mathrm{~min}$. The incubation with anti- $\beta 1$ antibody had no effect when applied alone but prevented the effect of TSP-1 on GluA2-AMPARs (Fig. $1 E)$, GluA1-AMPARs (data not shown), and GlyRs (Fig. 1F). In contrast, anti- $\beta 3$ antibody alone reduced AMPARs and increased GlyRs occluding the TSP-1 effect (Fig. $1 E, F$ ). Thus, TSP-1 could act via the activation of $\beta 1$-integrins and/or the inactivation of $\beta 3$-integrins.

Integrins link the ECM to the cytoskeleton and participate in the remodeling of F-actin in synapses (McGeachie et al., 2011). We quantified the amount of F-actin at synapses in triple labeling experiments using fluorescent phalloidin and antibodies against PSD95 and gephyrin (Fig. 1 G1-2). At excitatory synapses TSP-1 transiently decreased phalloidin staining (TSP 10 min: $-13.2 \%$ of control; TSP $60 \mathrm{~min}:-3.1 \%$, Fig. 1 G1). No changes were 
A
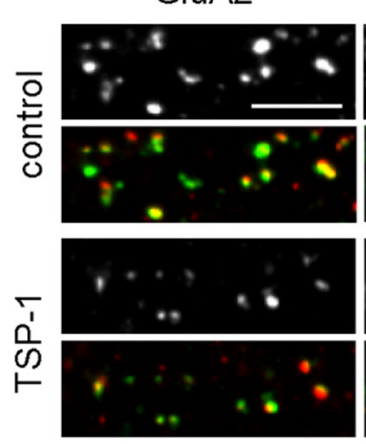

c

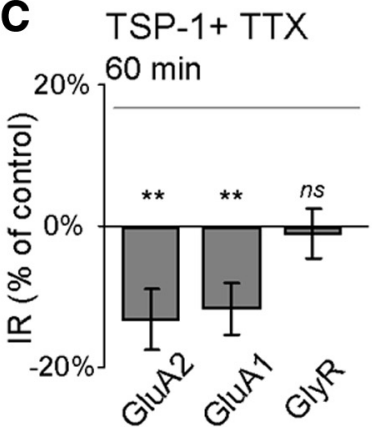

\section{G1}

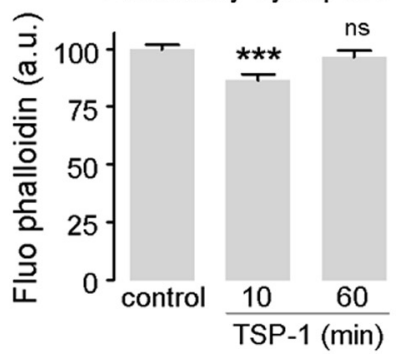

GluA1
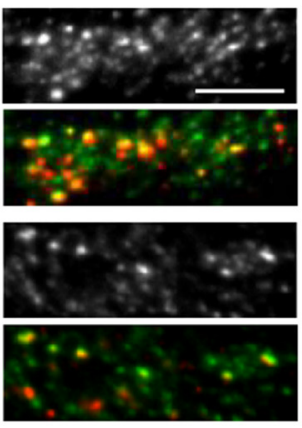

D GlyR

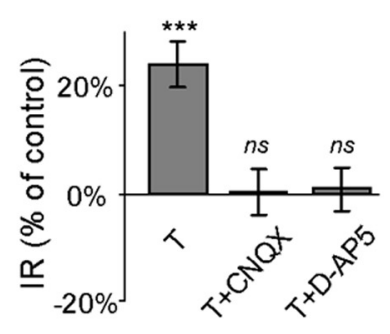

G2

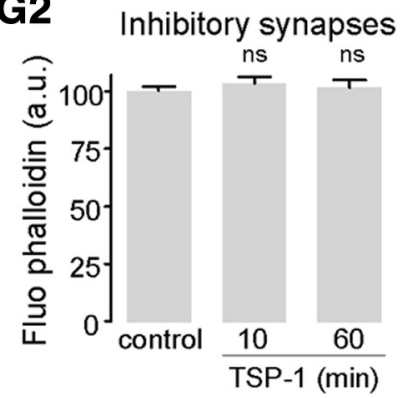

GlyR

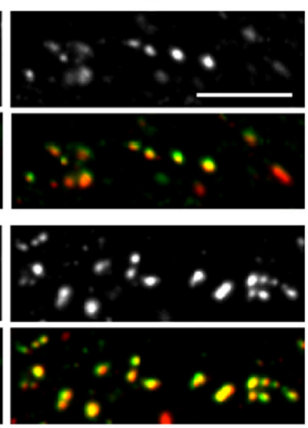

E GluA2

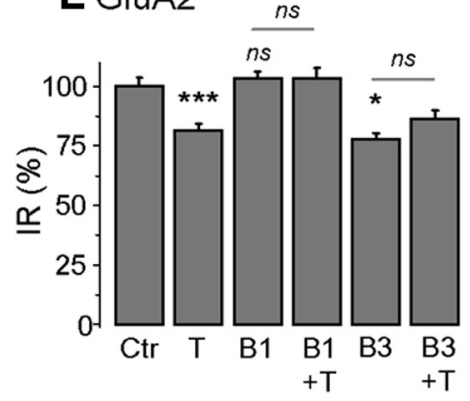

H1 GluA1

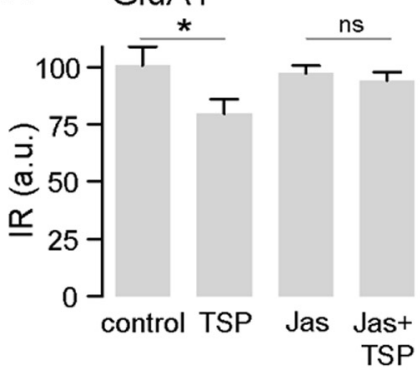

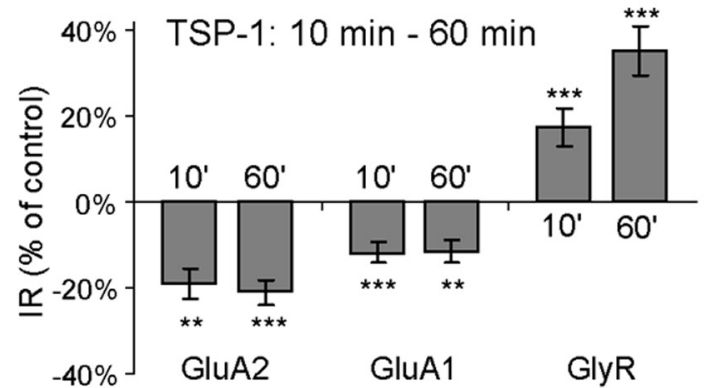

F GlyR

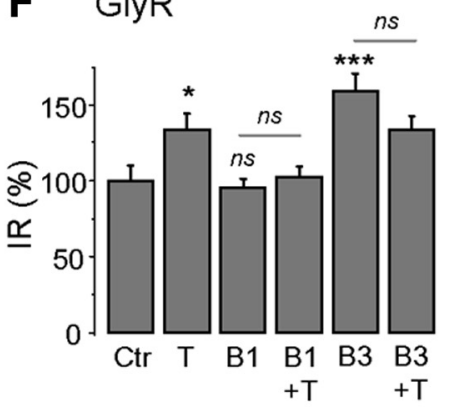

\section{H2 GluA2}

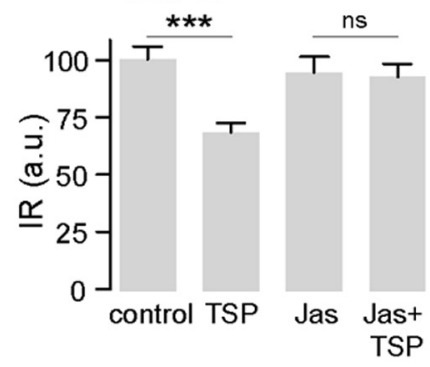

Figure 1. Differential effects of TSP-1 on the amount of excitatory and inhibitory receptors at synapses. A, Receptor IR in control conditions (top) or after $1 \mathrm{~h} \mathrm{TSP-1} \mathrm{treatment} \mathrm{(bottom).} \mathrm{Double}$ immunodetection of receptors (green) and their corresponding scaffolding molecules (red): GluA2-AMPAR and PSD95 (left), GluA1-AMPAR and PSD95 (center) or $\alpha 1$-GlyR and gephyrin (right). Scale bar, $5 \mu \mathrm{m} . \boldsymbol{B}-\boldsymbol{F}$, Quantification of the fluorescence associated with the indicated receptors. $\boldsymbol{B}$, Variation of receptor IR (\% of control) after 10 or 60 min of TSP-1 treatment ( $n=60$, ANOVA and Tukey test). $\boldsymbol{C}$, Variation of the indicated receptor IR (\% of control) after application of TSP-1 (60 min) in the presence of TTX ( $n=40-60, t$ test). $\boldsymbol{D}$, Variation of the GlyR-IR after application of TSP-1 (60 $\mathrm{min}$ ) alone (T) or in the presence of CNQX (T+CNQX) or D-AP5 (T+D-AP5). Drugs were added 10 min before TSP-1 ( $n=40-60, t$ test). $\boldsymbol{E}$, $\boldsymbol{F}$, Normalized IR associated with synaptic GluA2 (E) and GlyR $(\boldsymbol{F})$ in control conditions (Ctr) or after incubation with TSP-1 (T), anti- $\beta 1$ integrin antibody (B1), anti- $\beta 1$ antibody before TSP-1 (B1 $+\mathrm{T})$, anti- $\beta 3$ integrin antibody (B3) or anti- $\beta 3$ antibody before TSP-1 (B3+T). Treatments lasted 10 min in each case ( $n=15-31, t$ test). G1, G2, Normalized fluorescence of phalloidin colocalized with PSD-95-IR (G1) or gephyrin-IR (G2) in control conditions (control) or after incubation with TSP-1 for the indicated times ( $n=86$-181, ANOVA and Tukey test). H1, H2, Quantification of IR associated with synaptic GluA1 (H1) or GluA2 (H2) in control conditions or after treatment with TSP-1 (TSP, $10 \mathrm{~min})$, jasplakinolide (Jas), or jasplakinolide and TSP-1 (Jas + TSP) $(n=20-47, t$ test). All values are the mean \pm SEM. Ns, not significant; $\left.{ }^{*} p<0.05 ;{ }^{* *} p<0.01 ;{ }^{* * *} p<0.001\right)$.

observed at inhibitory synapses (Fig. 1 G2). Actin depolymerization was necessary as the stabilization of actin filaments with jasplakinolide abolished the reduction of GluA1 IR and GluA2 IR (Fig. $1 \mathrm{H} 1, \mathrm{H} 2)$.

In retinal ganglion cells, TSP-induced excitatory synapse formation (Eroglu et al., 2009) by binding to $\alpha 2 \delta 1$ calcium channel regulatory subunit. Gabapentin antagonizes TSP binding to $\alpha 2 \delta 1$ inhibiting TSP-induced excitatory synapse formation (Eroglu et al., 2009). We applied gabapentin ( $10 \mu \mathrm{M}, 60 \mathrm{~min})$ to our cultures to see whether it could block TSP effect on postsynaptic receptors. However, gabapentin alone modified the accumulation of receptors and scaffolding molecules in a different way than TSP-1, precluding its utilization as a blocker of TSP- $\alpha 2 \delta 1$ interaction. After gabapentin treatment, GluA1 IR was not modified $(t$ test, $p=0.76$ ) but GluA2 IR and PSD95 IR were increased (1.55fold, $p<0.0001$ and 1.19-fold, $p=0.003$; respectively). At inhib- itory synapses, gabapentin did not affect gephyrin-IR $(p=0.98)$ but it increased GlyR IR (1.27-fold, $p<0.0001)$.

TSP also interacts with neuroligins (Xu et al., 2010). We propose that TSP could help the clustering of neuroligin and this could mediate the acceleration of synapse formation. Neuroligins could target TSP to synapses; however we did not observe a particular enrichment of TSP at synapses of our mature spinal cord neurons ( $45.68 \pm 2.45 \%$ of TSP-IR colocalized with synapsin IR).

In the hippocampus, the pharmacological perturbation of integrins leads to a reduction of AMPAR synaptic currents mediated by the enhanced internalization of GluA2 (Cingolani et al., 2008). We investigated receptor endocytosis by cell surface biotinylation. After 60 min of TSP-1 treatment, we observed reduced surface AMPARs and increased surface GlyRs levels (Fig. $2 A 1, A 2)$. In the presence of the dynamin inhibitor dynasore ( 80 $\mu \mathrm{M}$ added $10 \mathrm{~min}$ before TSP-1 application), which prevents the 

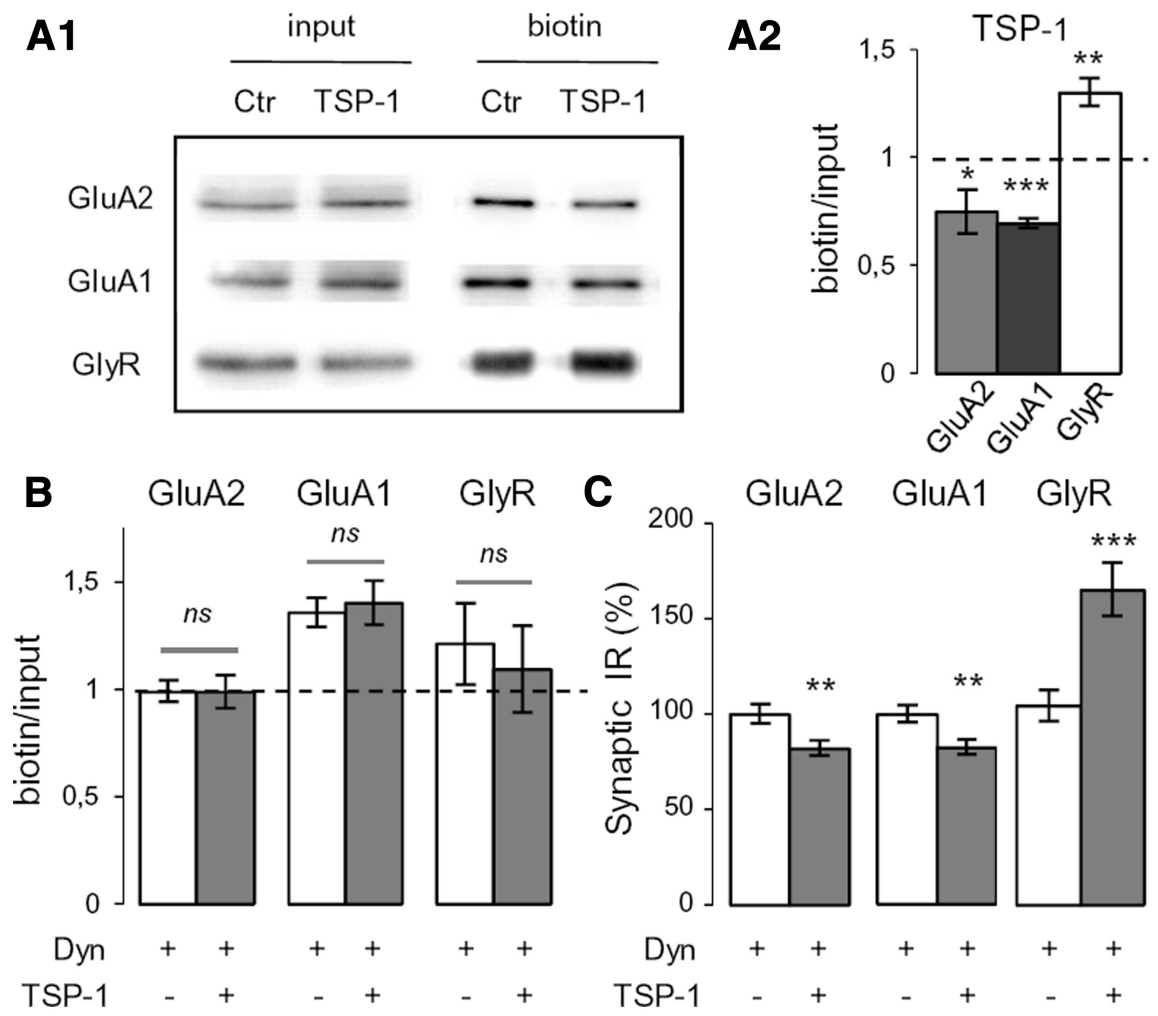

Figure 2. The TSP-1-induced regulations of synaptic glycine and AMPAR amounts are endocytosis-independent. $\boldsymbol{A} 1$, Representative Western blot of receptors. Neurons were treated (TSP-1, $60 \mathrm{~min}$ ) or not (Ctr) with TSP-1 before cell-surface biotinylation (input, total amount of protein; biotin, biotinylated receptors at the cell surface). $\mathbf{A}$, Mean ratio of surface to total receptor levels in TSP-1 conditions, normalized by the control ratio (mean $\pm \mathrm{SEM} ;{ }^{*} p<0.05,{ }^{* *} p<0.01,{ }^{* * *} p<0.001 ; t$ test). $\boldsymbol{B}$, Normalized mean ratio of surface receptor/total receptor level in cells treated only with dynasore (white) or with dynasore and TSP-1 (gray, dynasore added $10 \mathrm{~min}$ before TSP-1) (mean \pm SEM; ns, not significant, $t$ test). $C$, Normalized fluorescence intensity associated with synaptic GluA2, GluA1, and GlyR after inhibition of endocytosis by dynasore as in $\boldsymbol{B}$. Cells were treated or not with TSP-1 (mean \pm SEM; ${ }^{* *} p<0.01,{ }^{* * *} p<0.001, t$ test; $n=40$ ).

internalization of endocytic vesicles (Macia et al., 2006), these changes were abolished (Fig. 2B). When endocytosis was prevented by dynasore, the changes in the amount of receptors at synapses were still observed (Fig. 2C). Therefore, within the time course of this experiment, the modifications observed at synapses were independent of the endocytosis of receptors. This result suggested that instead TSP-1 modified the capacity of synapses to capture and retain receptors. Indeed the facilitation of AMPAR diffusion of synapses increases their availability for endocytosis (Zhou et al., 2001; Anggono and Huganir, 2012).

\section{The dynamics of synaptic AMPARs and GlyRs are modified by TSP-1}

As receptors enter and exit synapses by lateral diffusion, the number of receptors at synapses results from an equilibrium between the synaptic and the extrasynaptic population (Triller and Choquet, 2008). We analyzed the diffusion of AMPARs and GlyRs using quantum dot single-particle tracking (SPT). Quantum dots were detected with a pointing accuracy of $10-20 \mathrm{~nm}$ and tracked at $13 \mathrm{~Hz}$. Synapses were labeled with FM4-64, and the portions of trajectories overlapping FM4-64 stains were defined as synaptic. The mean square displacement (MSD) as a function of time interval was used to extract the diffusion coefficient $(D)$ as previously described (Charrier et al., 2010). TSP-1 was applied for the indicated times (10, 30 , or $60 \mathrm{~min}$ ) before the labeling for SPT.

The diffusion of extrasynaptic GluA2 or GluA1 did not change (KW and Dunn test, $p>0.05$ ), whereas extrasynaptic GlyR was slowed after 30 and 60 min of treatment $(p<0.0001$ for both, no significant changes after $10 \mathrm{~min}$ ). Regarding synaptic receptors, synaptic AMPARs diffused faster when cultures were treated with TSP-1 for only $10 \mathrm{~min}$ (Fig. 3A1). These effects were still observed when the treatment lasted $60 \mathrm{~min}$ in the case of synaptic GluA2-AMPARs (median $D$ in $10^{-3}$ $\mu \mathrm{m}^{2} / \mathrm{s}^{-1}$; ctr, 3.40; TSP $10 \mathrm{~min}, 6.69$; TSP $30 \mathrm{~min}, 4.24$; TSP $60 \mathrm{~min}$, 5.16; Fig. 3A1) but not in the case of GluA1 (median of synaptic $D$ in $10^{-3} \mu \mathrm{m}^{2} / \mathrm{s}^{-1}$; ctr, 1.39 ; TSP $10 \mathrm{~min}, 2.39$; TSP $30 \mathrm{~min}$, 2.12; TSP $60 \mathrm{~min}, 0.87$; Fig. 3A2). The time course of the changes in GlyR mobility in synapses was different. It was not significantly modified after 10 min of TSP-1 treatment, but it was progressively slowed down after longer incubation times (median of synaptic $D$ in $10^{-3} \mu^{2} / \mathrm{s}^{-1}$; ctr, 1.92; TSP 10 min, 1.86; TSP $30 \mathrm{~min}, 0.77$; TSP $60 \mathrm{~min}$, 0.48; Fig. $3 A 3)$, confirming our previous results (Charrier et al., 2010). GluA2AMPARs significantly reduced their dwell time following incubation with TSP-1 (Fig. 3B1). GluA1 showed a tendency toward a decrease after $10 \mathrm{~min}$ but an increase after longer $(60 \mathrm{~min})$ treatments (but these changes were not significant, Fig. 3B2). Under the same experimental conditions, GlyR did not modify their dwell time (Fig. 3B3).

Together, these data indicated that TSP-1 rapidly destabilized AMPARs leading to the reduction of receptor number at synapses. In contrast, GlyRs were progressively captured leading to their gradual accumulation at synapses. Synaptic GluA1AMPARs were only transiently accelerated. Together with the increased endocytosis, these results suggest that for these receptors a new equilibrium was rapidly reached after the internalization of the fast diffusing receptors.

\section{TSP-1 reverses the TNF $\alpha$-induced changes in synaptic receptors}

In hippocampal neurons, TNF $\alpha$ modifies excitatory and inhibitory synaptic transmission by increasing the insertion of GluA1containing AMPARs and reducing the surface amount of GABA receptors (Stellwagen et al., 2005). Therefore, we compared the IR of synaptic GluA1-AMPARs and GlyRs after TNF $\alpha$ ( $60 \mathrm{~nm}, 30$ $\mathrm{min}$ ) or TSP-1 (8 nM, $60 \mathrm{~min})$ treatment in triple immunolabeling experiments (synapses were identified by the presynaptic protein Piccolo; Fig. 4A1). In this aim, the 2D-isodensity contours of GluA1 and GlyR IR obtained after TSP-1 and TNF $\alpha$ treatment were superimposed (Fig. 4A2). TNF $\alpha$ had the opposite effect to TSP-1 and induced an increase in GluA1 IR and a decrease in GlyR IR. These data were confirmed in experiments where GluA1 and GlyR were codetected with their corresponding scaffolding proteins PSD95 and gephyrin, respectively (Fig. 4B). TNF $\alpha$ had no effect on synaptic GluA2 IR ( $p=0.16$, Fig. $4 B$ ). Lower concentrations of TNF $\alpha(0.6$ and $6 \mathrm{nM})$ also significantly reduced GlyR (ANOVA and Tukey test, $p<0.05$ ) but did not significantly modify GluA1 $(p>0.05)$. 


\section{A1}

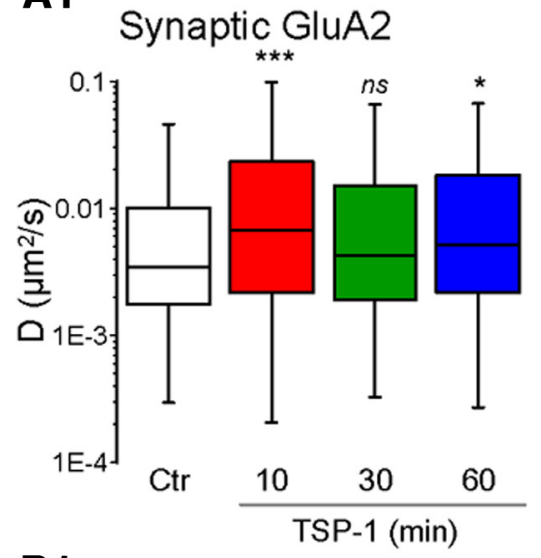

B1

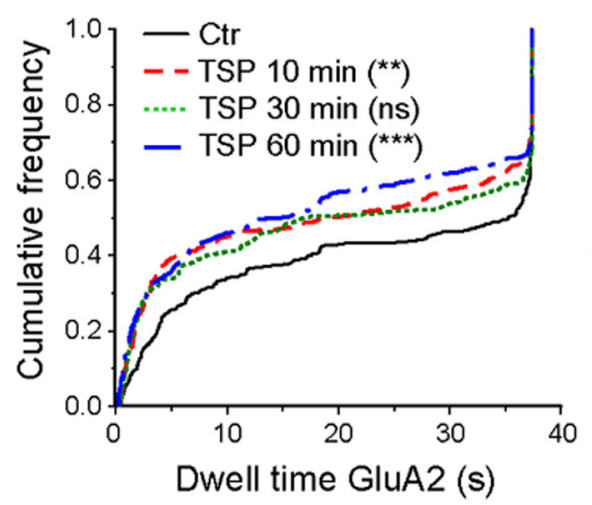

A2 Synaptic GluA1

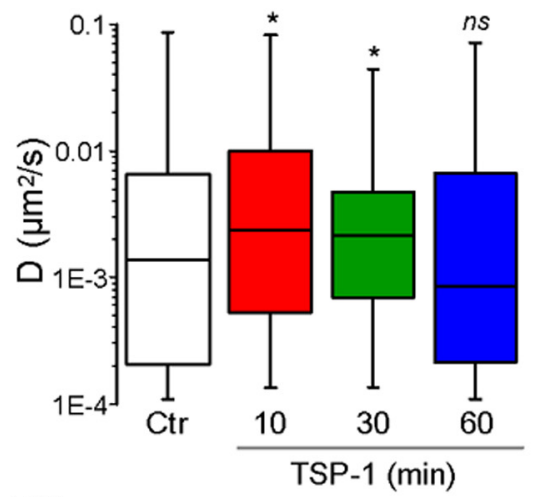

B2

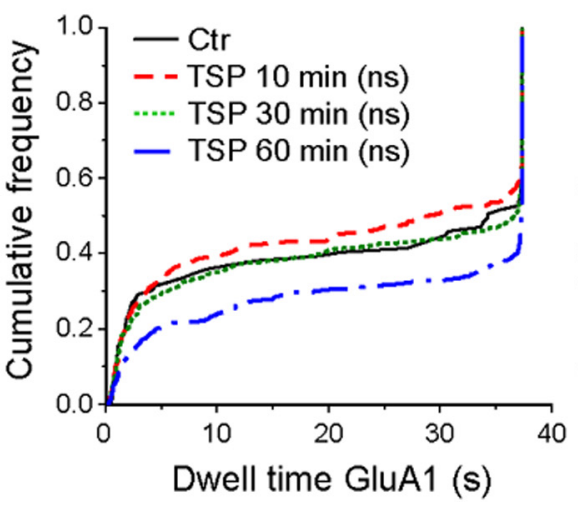

A3

Synaptic GlyR

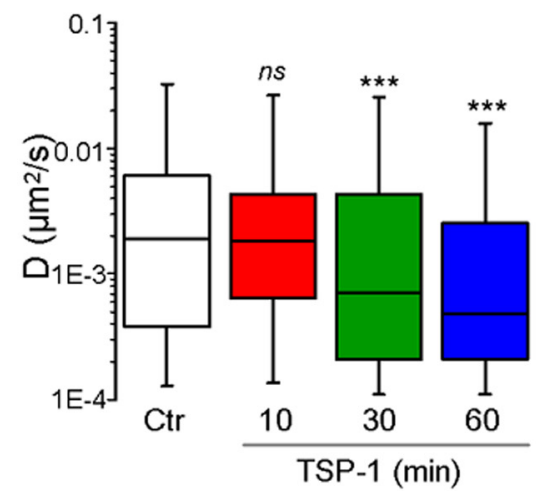

B3

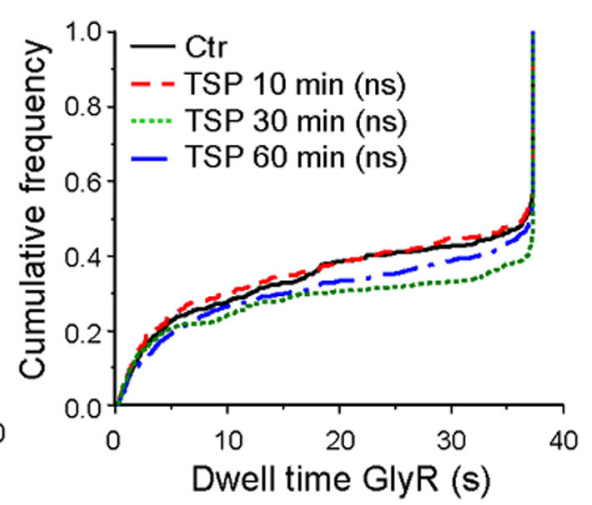

Figure 3. Reverse effects of TSP-1 on synaptic AMPAR and GlyR dynamics. A1-A3, Distribution of diffusion coefficients for synaptic GluA2 (A1), GluA1 (A2) or GlyR (A3) in control conditions (Ctr) or after the indicated durations of TSP-1 treatment (median, 25 and 75\% IQR; ns, not significant; ${ }^{*} p<0.05,{ }^{* * *} p<0.001$, KW and Dunn test; $n=97-477$ ). B1-B3, Cumulative frequency distribution of dwell times of the receptors in $\boldsymbol{A}$ (KW and Dunn test; $n$ s, not significant; ${ }^{* *} p<0.01,{ }^{* * *} p<0.001$ ).

To investigate whether TSP-1 could reverse the changes induced by TNF $\alpha$, cultures were treated with TNF $\alpha$ for $30 \mathrm{~min}$, rinsed, and subsequently incubated $(60 \mathrm{~min})$ in their original medium with or without TSP-1. The recovery after TSP-1 treatment was TSP-1 dose-dependent, with significant changes when applying TSP-1 at $8 \mathrm{~nm}$ (data not shown). Neurons treated with TNF $\alpha$ alone had increased GluA1 $(+33 \pm 6 \%)$ and decreased GlyR IR $(-20 \pm 4 \%)$, whereas those treated with TNF $\alpha$ followed by TSP-1 ( $8 \mathrm{nM})$ containing medium returned to control levels (Fig. 4B). TSP-1 still decreased GluA2 in cells treated with TNF $\alpha$ $(-23 \pm 4 \%$; Fig. $4 B)$. These results have also been seen on pure neuronal cultures (data not shown), indicating that the presence of glial cells was not necessary for this reversion.

Changes in intracellular $\mathrm{Ca}^{2+}\left(\mathrm{Ca}_{\mathrm{i}}{ }^{2+}\right)$, reflecting global neuronal activity, were monitored using the calcium indicator Fluo-4 AM. 4-Aminopyridine (4-AP, $50 \mu \mathrm{M})$, a potassium channel blocker, was applied to increase neuronal and synaptic activities to check whether the global network excitability was modified. As expected, the addition of 4-AP increased Fluo-4 AM intensity (Fig. 4C). Pretreatment by TSP-1 (60 min) lowered the 4-APdependent Fluo-4 AM fluorescence increase, whereas incubation with TNF $\alpha$ alone (60 nM, $30 \mathrm{~min}$ ) enhanced this effect (Fig. 4C). Thus, the changes in the amount of synaptic receptors due to TSP- 1 or TNF $\alpha$ treatments were correlated with changes in the overall excitability of neurons. In contrast, when TNF $\alpha$ treatment was followed by TSP-1, the intensity level of Fluo-4 AM remained similar to that seen in control conditions (Fig. 4C). A similar result was obtained when neurons were first treated with
TSP-1 subsequently incubated with TNF $\alpha$ at the same concentrations (data not shown).

TNF $\alpha$-driven increased AMPAR activity potentiates excitotoxicity in spinal cord (Ferguson et al., 2008) and in hippocampal neurons (Leonoudakis et al., 2008). Thus, cellular death was quantified in cultured spinal cord neurons exposed to TNF $\alpha$ (150 min) with or without addition of TSP-1 (120 min, added $30 \mathrm{~min}$ after TNF $\alpha$ ). The DAPI-stained nuclei were classified as normal or apoptotic nuclei depending on their morphology (Doonan and Cotter, 2008). The proportion of apoptotic nuclei was increased by TNF $\alpha$ ( $+15 \%$ vs control situation, $p<0.001, \chi^{2}$ test $)$ but this TNF $\alpha$-related proapoptotic effect was reverted by TSP-1 $(-10 \%$ vs control situation, $p<0.001)$. Together, our results show that TSP-1 counteracted TNF $\alpha$-induced changes in synaptic transmission and neuronal vulnerability.

\section{Discussion}

We report that TSP-1 regulates the amount of synaptic inhibitory and excitatory receptors in mature cultured spinal cord neurons. Our results suggest that in addition to its role in developmental or injury-induced synaptogenesis (Liauw et al., 2008; Lo et al., 2011; for review, see Risher and Eroglu, 2012), TSP may tune the balance between excitation and inhibition in the adult CNS via integrin signaling.

Integrins are bidirectional, allosteric signaling molecules mediating the interaction between the ECM and the cytoskeleton (Hynes, 2002). In addition to their well established roles in cell survival and cell motility, integrins participate in the adjust- 

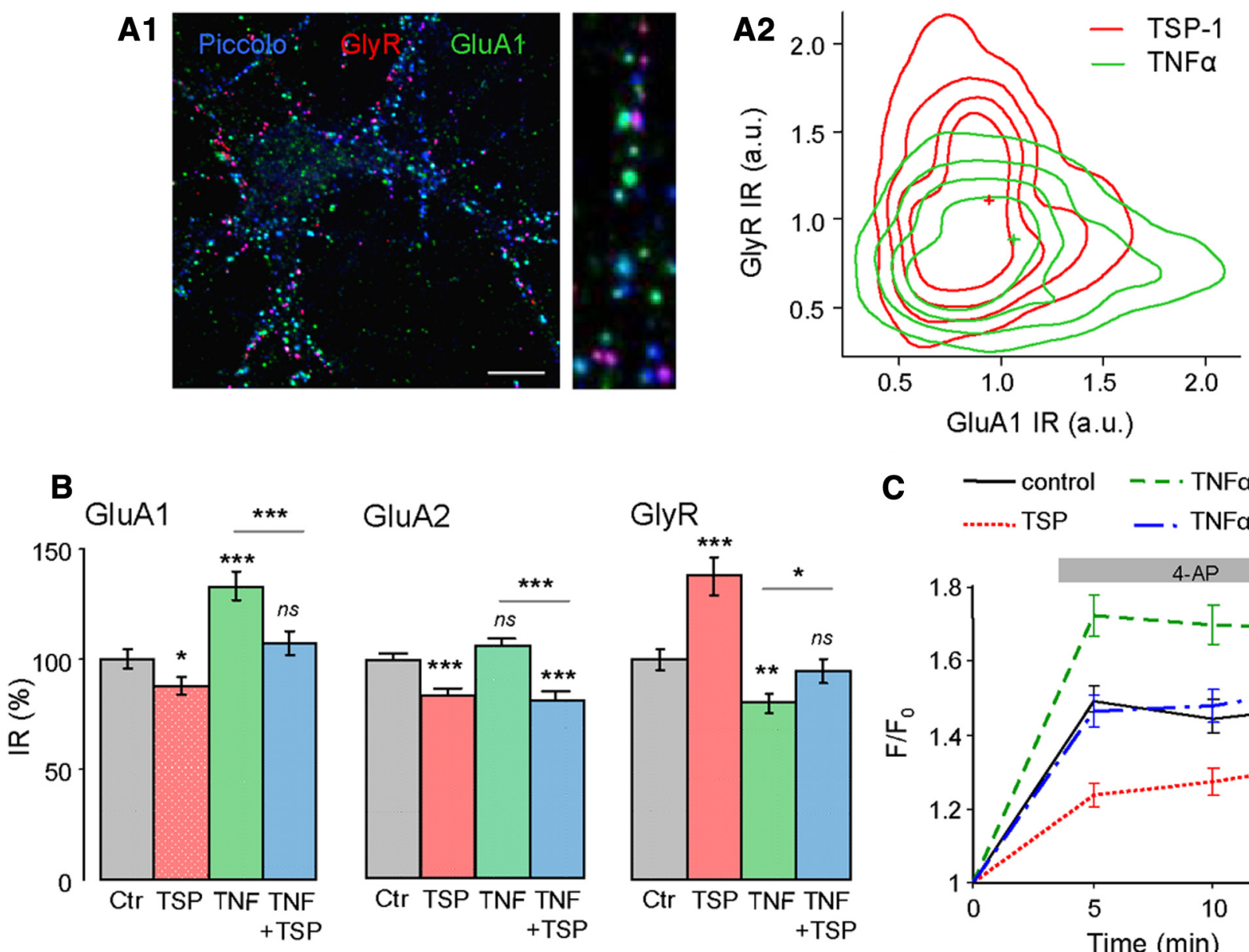

C control $--\cdot \cdot \mathrm{TNFa}$ .. TSP $\quad-$. TNFa + TSP-1

Figure 4. TSP-1 reverses TNF $\alpha$-induced modifications of synaptic receptors. A1, Overlay image of the triple immunodetection of GlyR (red), GluA1 (green), and Piccolo (blue) staining. Right, higher-magnification. A2, Iso-density contours of the normalized fluorescence intensity of GluA1 ( $x$-axis) and GlyR ( $y$-axis) clusters at synapses under TSP-1 (red), or TNF $\alpha$ (green) conditions. The intensity of fluorescence (arbitrary units) of GluA1 and GlyR clusters was averaged in each dendrite and normalized to control values. The distributions of fluorescence intensity are presented as density plots from a Kernel density estimation (performed in R software). The contours represented iso-density curves for densities $0.2,0.4,0.6$, and 0.8 from outside to inside ( $p<0.001, T^{2}$ Hotelling test, nTSP-1 = 328, nTNF $\alpha=331$ ). B, Normalized fluorescence intensity associated with synaptic GluA1, GluA2, and GlyR in control conditions, after TSP-1, TNF $\alpha$, or TNF $\alpha$ followed by TSP-1 application (mean \pm SEM; ns, not significant; ${ }^{*} p<0.05 ;{ }^{* *} p<0.01 ;{ }^{* * *} p<0.001 ; t$ test, $\left.n=60\right)$. C, Intracellular $\mathrm{Ca}^{2+}$ monitored by fluorescence intensity of Fluo4AM $\left(\mathrm{F} / \mathrm{F}_{0} ;\right.$ mean \pm SEM) on neurons before and after 4-AP (50 $\mu \mathrm{M}$ ) application (gray bar) in control conditions ( $n=86)$, or after TSP-1 ( $n=84, p<0.001$ ANOVA), TNF $\alpha(n=80, p<0.001)$, or TNF $\alpha$ plus TSP-1 $(n=91$, not significant) treatment.

ment of synaptic strength via actin cytoskeleton remodeling (McGeachie et al., 2011). Integrins signal to cytoskeleton either to induce the polymerization or to control the depolymerization of actin. $\beta 1$-containing integrins were proposed to participate in the stabilization of LTP through the consecutive disassembly and reassembly of adhesive and cytoskeletal elements (McGeachie et al., 2011). Actually, actin depolymerization increases the diffusion of receptors in and out synapses (Charrier et al., 2006; Rust et al., 2010). In our experiments, we observed a transient decrease in the level of F-actin at excitatory synapses and concomitantly AMPAR diffused more. This decrease in F-actin likely contributed to the escape of AMPARs because the stabilization of actin filaments prevented the loss of synaptic receptors. Therefore actin depolymerization helped the diffusion of AMPARs out of synapses where they became available to the endocytotic machinery and were internalized (Zhou et al., 2001).

Blocking $\beta 1$-integrins prevented the modification of synaptic receptor numbers by TSP-1 for both GlyRs (Charrier et al., 2010) and AMPARs (this work). However, anti- $\beta 3$ antibodies mimicked and occluded the loss of AMPARs due to TSP-1. Thus the results presented here are also compatible with an inactivation of $\beta 3$-integrins signaling or the disruption of their interactions with other ligands (Pozo et al., 2012). Indeed $\beta 3$ integrins stabilize AMPARs at the postsynaptic membrane and these receptors are selectively endocytosed upon disruption of $\beta 3$-ECM interactions (Cingolani et al., 2008; Pozo et al., 2012). Therefore $\beta 1$ - and $\beta 3$-integrins are involved in the downregulation of synaptic receptors by TSP-1.

In neurons, the $\alpha 2 \delta 1$ calcium channel regulatory subunit and neuroligins are ligands for TSP mediating its synaptogenic activity (Eroglu et al., 2009; Xu et al., 2010). Gabapentin has been used to antagonize TSP binding to $\alpha 2 \delta 1$ in retinal ganglion cells (Eroglu et al., 2009). However, we observed significant effects of this drug applied alone precluding its utilization in our cultures. Beside the fact that other type of neurons was used in previous studies, neurons could respond differently during and after synaptogenesis. Indeed, the interaction of TSP and neuroligins accelerates synapse formation in hippocampal neurons only during a short time window (between 5 and $8 \mathrm{~d}$ after plating) (Xu et al., 2010).

The number of receptors at synapses depends on the number of receptors at the cell surface and their diffusion and their cap- 
ture at synaptic loci, the latter being regulated by the number of binding sites (i.e., of scaffolding molecules) and the affinity of the receptor-scaffold interaction (Renner et al., 2008; Triller and Choquet, 2008). In the case of GlyR, its surface level increased, together with the amount of synaptic receptors and gephyrin. Therefore, GlyRs were progressively recruited thanks to the increased number of gephyrin scaffolding sites. In the case of AMPARs, TSP-1 decreased the amount of receptors at the cell surface and at synapses. Furthermore, GluA2-AMPARs spent less time at the synapse with no change in PSD95 IR. This suggests that TSP-1 destabilized AMPARs by modifying their interaction with PSD95 and/or with proteins, such as TARPs (Bats et al., 2007).

The differences observed between inhibitory and excitatory synapses are noteworthy. In case of excitatory synapses, no synaptic activity was needed, there was a transient depolymerization of F-actin cytoskeleton, and the PSD 95 IR did not change. At inhibitory synapses, the glutamatergic activity was needed, the actin cytoskeleton was not modified, and gephyrin IR increased. The excitatory activity could be required for the signaling of $\beta 1$ integrins through CaMKII, which modulates the amount of GlyR at synapses by increasing the amount of gephyrin (Charrier et al., 2010). Increased excitatory transmission results in the rapid homeostatic regulation of the inhibitory transmission (Lévi et al., 2008). Our results reveal that TSP-1 shifted the level of the homeostatic regulation toward a reduced excitability by modifying in parallel excitatory and inhibitory receptors.

GluA1 and GluA2-containing AMPARs where not always modulated in parallel. TSP-1 decreased the synaptic amount of both but had a stronger effect on GluA2 $(\sim 19 \%$ in case of GluA2, $\sim 12 \%$ for GluA1). As both GluA1 and GluA2 can be assembled in the same receptor, TSP-1 could target exclusively GluA2AMPARs. Indeed, TSP-1 significantly decreased the dwell time of GluA2-AMPARs, suggesting a modification of the interaction between this subunit and the scaffold (Renner et al., 2012). The effect on GluAl is then likely to depend on the relative ratio of GluA1 to GluA2 in the plasma-membrane. In cells treated with TNF $\alpha$ (which only increased GluA1), TSP-1 reduced GluA2 AMPARs and GluA1 in similar proportions ( $\sim 23 \%$ and $\sim 20 \%$, respectively).

Diffusion analysis also pointed out differences between GluA1 and GluA2. Synaptic GluA1-AMPARs were only transiently accelerated. Together with the increased endocytosis, this result suggests that for these receptors a new equilibrium was rapidly reached. As endocytosis occurs exclusively out of the PSD (Anggono and Huganir, 2012), the internalization selectively reduces the amount of mobile receptors. GluA2-containing AMPAR were more mobile than GluA1 ones; thus the mobile fraction of GluA2 was more important. Our results show that mobile GluA2 were still abundant even after the endocytosis of part of them. In case of GluA1, the increased endocytosis due to TSP treatment was enough to deplete the mobile fraction. This was translated into a general reduction of mobility at $60 \mathrm{~min}$, because the mobile fraction was reduced and the receptors remaining at synapses were the ones which were still trapped by the scaffold.

In the adult CNS, TSP-1 is expressed following inflammation or injury (Risher and Eroglu, 2012), which also results in a TNF $\alpha$ mediated increase of neuronal excitability and ultimately to an enhanced neuronal vulnerability to excitotoxicity (Beattie et al., 2010). Although TNF $\alpha$ acts rapidly after an insult (less than an hour) (Ferguson et al., 2008), TSP is expressed $4-6 \mathrm{~h}$ later (Lin et al., 2003; Tran and Neary, 2006). This may have protective consequences because TSP-1 counteracted TNF $\alpha$-induced modifica- tions of synaptic receptors leading to the recovery of excitability to a control level.

\section{References}

Anggono V, Huganir RL (2012) Regulation of AMPA receptor trafficking and synaptic plasticity. Curr Opin Neurobiol 22:461-469. CrossRef Medline

Bats C, Groc L, Choquet D (2007) The interaction between stargazin and PSD-95 regulates AMPA receptor surface trafficking. Neuron 53:719734. CrossRef Medline

Beattie MS, Ferguson AR, Bresnahan JC (2010) AMPA-receptor trafficking and injury-induced cell death. Eur J Neurosci 32:290-297. CrossRef Medline

Blake SM, Strasser V, Andrade N, Duit S, Hofbauer R, Schneider WJ, Nimpf J (2008) Thrombospondin-1 binds to ApoER2 and VLDL receptor and functions in postnatal neuronal migration. EMBO J 27:3069-3080. CrossRef Medline

Bornstein P, Agah A, Kyriakides TR (2004) The role of thrombospondins 1 and 2 in the regulation of cell-matrix interactions, collagen fibril formation, and the response to injury. Int J Biochem Cell Biol 36:1115-1125. CrossRef Medline

Carlson CB, Lawler J, Mosher DF (2008) Structures of thrombospondins. Cell Mol Life Sci 65:672-686. CrossRef Medline

Charrier C, Ehrensperger MV, Dahan M, Lévi S, Triller A (2006) Cytoskeleton regulation of glycine receptor number at synapses and diffusion in the plasma membrane. J Neurosci 26:8502-8511. CrossRef Medline

Charrier C, Machado P, Tweedie-Cullen RY, Rutishauser D, Mansuy IM, Triller A (2010) A crosstalk between betal and beta3 integrins controls glycine receptor and gephyrin trafficking at synapses. Nat Neurosci 13: 1388-1395. CrossRef Medline

Choi JI, Svensson CI, Koehrn FJ, Bhuskute A, Sorkin LS (2010) Peripheral inflammation induces tumor necrosis factor dependent AMPA receptor trafficking and Akt phosphorylation in spinal cord in addition to pain behavior. Pain 149:243-253. CrossRef Medline

Christopherson KS, Ullian EM, Stokes CC, Mullowney CE, Hell JW, Agah A, Lawler J, Mosher DF, Bornstein P, Barres BA (2005) Thrombospondins are astrocyte-secreted proteins that promote CNS synaptogenesis. Cell 120:421-433. CrossRef Medline

Cingolani LA, Thalhammer A, Yu LM, Catalano M, Ramos T, Colicos MA, Goda Y (2008) Activity-dependent regulation of synaptic AMPA receptor composition and abundance by beta3 integrins. Neuron 58:749-762. CrossRef Medline

DeFreitas MF, Yoshida CK, Frazier WA, Mendrick DL, Kypta RM, Reichardt LF (1995) Identification of integrin alpha 3 beta 1 as a neuronal thrombospondin receptor mediating neurite outgrowth. Neuron 15:333-343. CrossRef Medline

Doonan F, Cotter TG (2008) Morphological assessment of apoptosis. Methods 44:200-204. CrossRef Medline

Eroglu C, Allen NJ, Susman MW, O’Rourke NA, Park CY, Ozkan E, Chakraborty C, Mulinyawe SB, Annis DS, Huberman AD, Green EM, Lawler J, Dolmetsch R, Garcia KC, Smith SJ, Luo ZD, Rosenthal A, Mosher DF, Barres BA (2009) Gabapentin receptor alpha2 $\delta$ - 1 is a neuronal thrombospondin receptor responsible for excitatory CNS synaptogenesis. Cell 139:380-392. CrossRef Medline

Ferguson AR, Christensen RN, Gensel JC, Miller BA, Sun F, Beattie EC, Bresnahan JC, Beattie MS (2008) Cell death after spinal cord injury is exacerbated by rapid TNF alpha-induced trafficking of GluR2-lacking AMPARs to the plasma membrane. J Neurosci 28:11391-11400. CrossRef Medline

Hynes RO (2002) Integrins: bidirectional, allosteric signaling machines. Cell 110:673-687. CrossRef Medline

Leonoudakis D, Zhao P, Beattie EC (2008) Rapid tumor necrosis factor alpha-induced exocytosis of glutamate receptor 2-lacking AMPA receptors to extrasynaptic plasma membrane potentiates excitotoxicity. J Neurosci 28:2119-2130. CrossRef Medline

Lévi S, Schweizer C, Bannai H, Pascual O, Charrier C, Triller A (2008) Homeostatic regulation of synaptic GlyR numbers driven by lateral diffusion. Neuron 59:261-273. CrossRef Medline

Liauw J, Hoang S, Choi M, Eroglu C, Sun GH, Percy M, Wildman-Tobriner B, Bliss T, Guzman RG, Barres BA, Steinberg GK (2008) Thrombospondins 1 and 2 are necessary for synaptic plasticity and functional recovery after stroke. J Cereb Blood Flow Metab 28:1722-1732. CrossRef Medline 
Lin TN, Kim GM, Chen JJ, Cheung WM, He YY, Hsu CY (2003) Differential regulation of thrombospondin-1 and thrombospondin-2 after focal cerebral ischemia/reperfusion. Stroke 34:177-186. CrossRef Medline

Lo FS, Zhao S, Erzurumlu RS (2011) Astrocytes promote peripheral nerve injury-induced reactive synaptogenesis in the neonatal CNS. J Neurophysiol 106:2876-2887. CrossRef Medline

Macia E, Ehrlich M, Massol R, Boucrot E, Brunner C, Kirchhausen T (2006) Dynasore, a cell-permeable inhibitor of dynamin. Dev Cell 10:839-850. CrossRef Medline

McGeachie AB, Cingolani LA, Goda Y (2011) A stabilising influence: integrins in regulation of synaptic plasticity. Neurosci Res 70:24-29. CrossRef Medline

Murphy-Ullrich JE, Iozzo RV (2012) Thrombospondins in physiology and disease: new tricks for old dogs. Matrix Biol 31:152-154. CrossRef Medline

Pozo K, Cingolani LA, Bassani S, Laurent F, Passafaro M, Goda Y (2012) $\beta 3$ integrin interacts directly with GluA2 AMPA receptor subunit and regulates AMPA receptor expression in hippocampal neurons. Proc Natl Acad Sci U S A 109:1323-1328. CrossRef Medline

Renner M, Specht CG, Triller A (2008) Molecular dynamics of postsynaptic receptors and scaffold proteins. Curr Opin Neurobiol 18:532-540. CrossRef Medline

Renner M, Schweizer C, Bannai H, Triller A, Lévi S (2012) Diffusion barriers constrain receptors at synapses. PLoS One 7:e43032. CrossRef Medline
Risher WC, Eroglu C (2012) Thrombospondins as key regulators of synaptogenesis in the central nervous system. Matrix Biol 31:170-177. CrossRef Medline

Rust MB, Gurniak CB, Renner M, Vara H, Morando L, Görlich A, SassoèPognetto M, Banchaabouchi MA, Giustetto M, Triller A, Choquet D, Witke W (2010) Learning, AMPA receptor mobility and synaptic plasticity depend on n-cofilin-mediated actin dynamics. EMBO J 29: 1889-1902. CrossRef Medline

Stellwagen D, Beattie EC, Seo JY, Malenka RC (2005) Differential regulation of AMPA receptor and GABA receptor trafficking by tumor necrosis factor-alpha. J Neurosci 25:3219-3228. CrossRef Medline

Tran MD, Neary JT (2006) Purinergic signaling induces thrombospondin-1 expression in astrocytes. Proc Natl Acad Sci U S A 103:9321-9326. CrossRef Medline

Triller A, Choquet D (2008) New concepts in synaptic biology derived from single-molecule imaging. Neuron 59:359-374. CrossRef Medline

Xu J, Xiao N, Xia J (2010) Thrombospondin 1 accelerates synaptogenesis in hippocampal neurons through neuroligin 1. Nat Neurosci 13:2224. CrossRef Medline

Zhou Q, Xiao M, Nicoll RA (2001) Contribution of cytoskeleton to the internalization of AMPA receptors. Proc Natl Acad Sci U S A 98:12611266. CrossRef Medline 